\title{
Resources
}




\section{2,000 years of Chinese acupuncture}

Text: Vivienne Lo and Volker Scheid; Design: Akio Morishima

The following plates are the second half of an exhibition designed for IASTAM in 2003. The first half was included in issue 1.1 of Asian Medicine. They are available electronically, or as posters, as a set or individually. For details apply to Emma Ford: e.ford@ucl.ac.uk. 


\section{Moxibustion}

Moxibustion, a form of heat treatment, was one of the earliest and most important methods for treating the channels. Being more accessible and cheaper than needles it was a popular and widespread treatment. The dried and ground leaves of mugwort (artemesia vulgaris) burnt on and over the body are first known in atropaic techniques used to protect the household from attack by demons. Nowadays, Chinese medical practitioners will burn it on the end of metal needles, use cigar-shaped rolls of moxibustion, or cones to stimulate particular points or painful parts of the body.

A Song dynasty painting depicting a country doctor burning moxibustion on a patient's back.

Image courtesy of the Needham Research Institute.

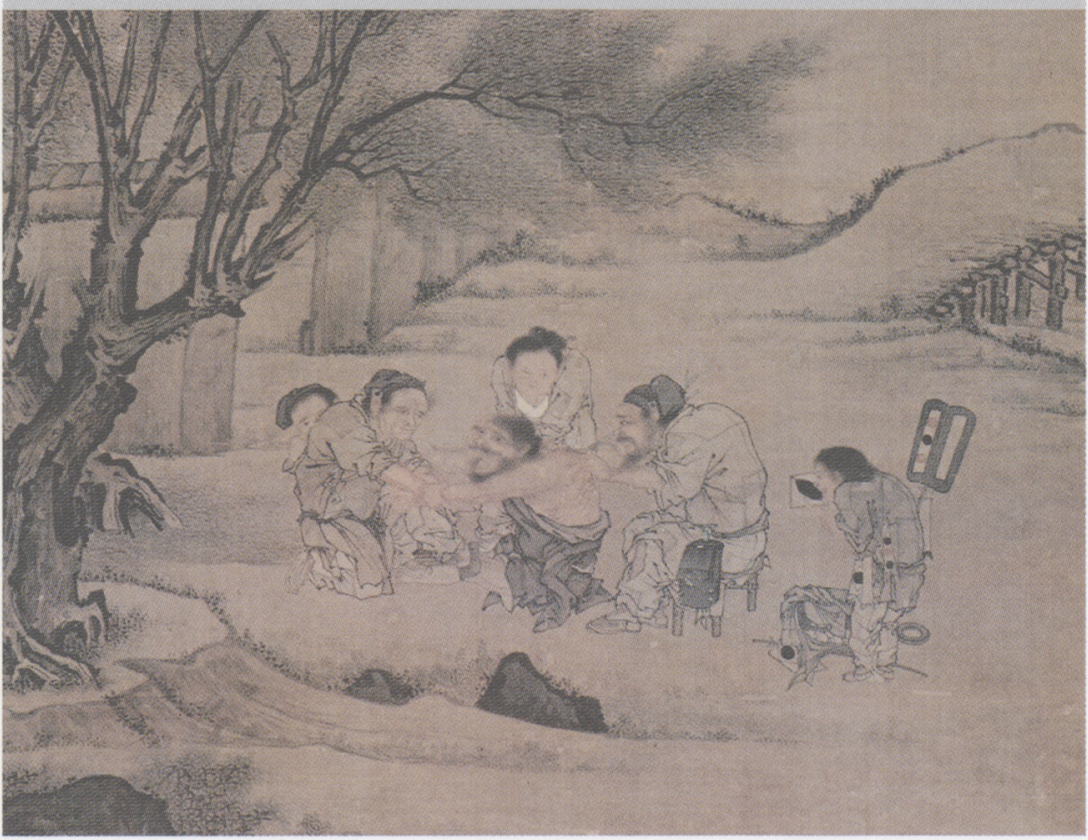




\section{The Earliest Surviving Moxibustion Charts}

Among the thousands of Buddhist manuscripts discovered a century ago in a hidden cave library at Dunhuang on the Silk Road were some 100 medical manuscripts. One damaged series of sketches of the body, now held in the British Library, gives simple instructions for the treatment of specific conditions with moxibustion. The figures constitute the earliest surviving moxibustion charts and pre-date the Northern Song acupuncture bronzes that lay out comprehensive networks of acupuncture loci, by some three or four centuries.

Characteristic of the Dunhuang archive is that it preserves a very wide variety of technical manuscripts in which we find intimate glimpses of popular medical theory and practice in Tang dynasty (618 - 907 CE) China at this Northwestern outpost of the empire.

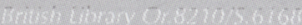

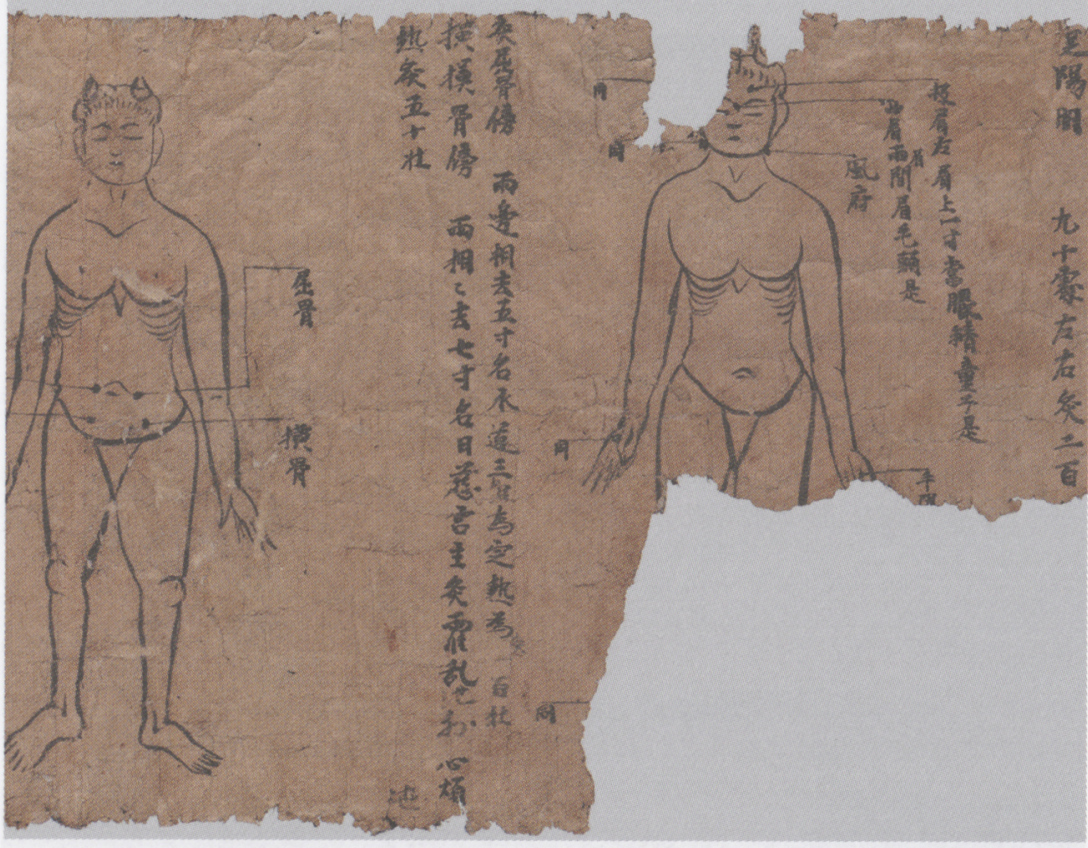




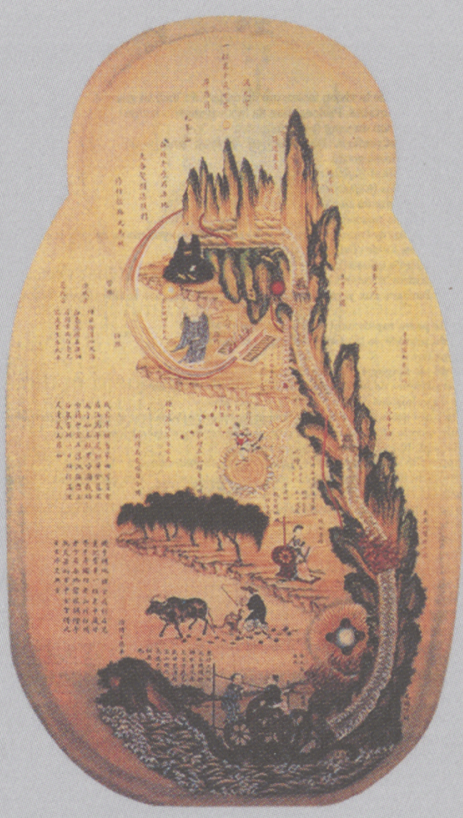

\section{Inner Alchemy}

Classical Chinese perceptions of the medical body mirrored the geographical, philosophical, political and religious realities of early China. The surface of the body was landscaped with mountain ranges and waterways, and it sparkled with representations of the sun and moon, stars and constellations in the names of anatomical and acupuncture locations. Patterns and hierarchies of imperial bureaucracy and administration structured the imagination of physiological process.

In mediaeval times Chinese 'inner alchemy' often associated with the Shangqing (Supreme Purity) school of Daoism, was one context within which lyrical image of the inner body flourished. Preceded by the older practice of compounding of elixirs from metals and minerals, 'Inner Alchemy' aims to produce an elixir through practices that refine the substances within the adept's body. 


\section{Nine Needles}

Classics of Chinese acupuncture tend to express dissatisfaction with the crude methods associated with early acupuncture. Yet much of the therapy described in one early treatise known as 'Nine Needles' describes petty surgery, blood-letting and massage. Needles for moving qi were of rare quality, likened to 'fine hair'.

A Ming (1368 - $1644 \mathrm{CE})$ reconstruction of the Nine Needles

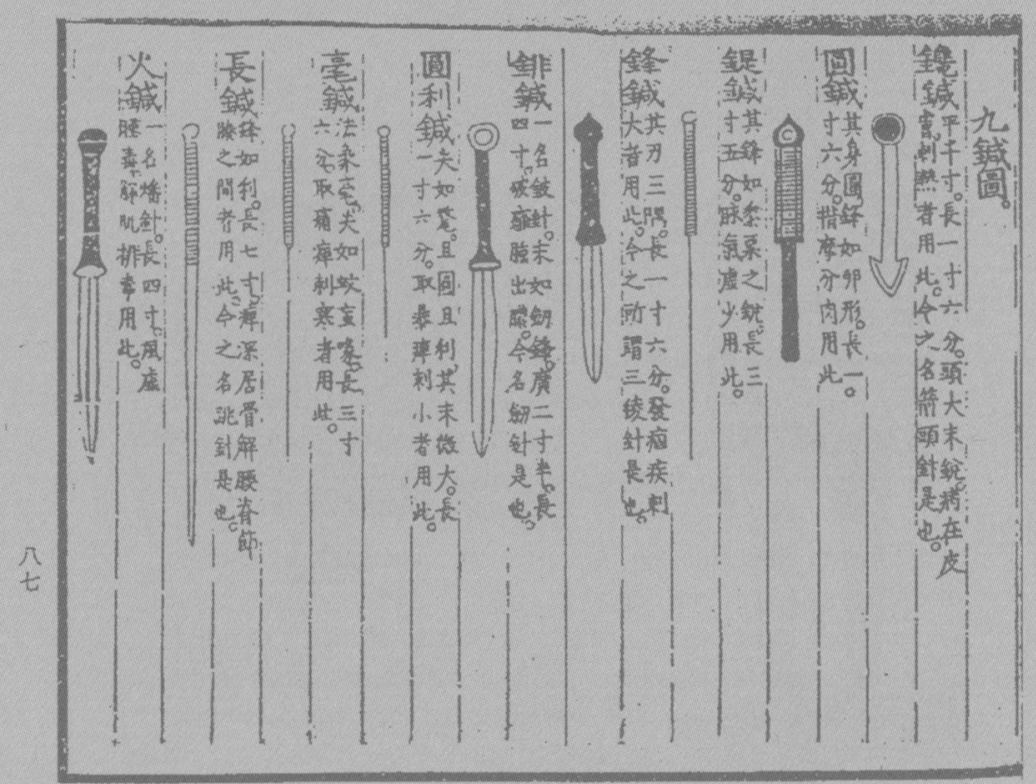




\section{The Song (960-1279 CE) Bronzes}

Imperial patronage of acupuncture flourished in the Tang period and was on the curriculum of the Song Imperial Medical College. In Song times scholars sought to systematise medical knowledge. Bronze acupuncture figurines were first cast by Wang Weiyi (11th century) for the purposes of teaching and examination. They clearly display the circulation networks and label each acupuncture point. When the model was covered with a layer of yellow wax and filled with water, medical students had to locate the required acupoint exactly with a needle, causing water to gush out of the model through the hole.

A bronze figurine made to imperial decree in $1727 \mathrm{CE}$ Photo: Wellcome Medical Museum
A fifteenth century interpretation of Wang Weiyi's bronzes Beijing National Museum of History
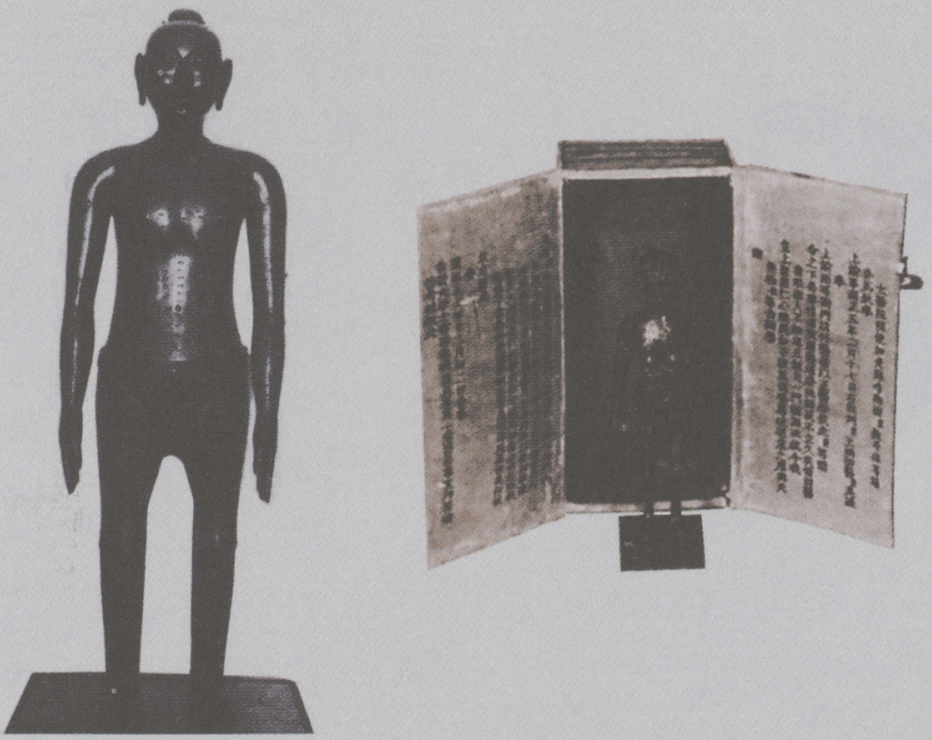


\section{Medical Plurality}

Surviving documentary evidence of acupuncture theory records the work of a scholarly medical elite. But throughout Chinese medical history we find traces of more popular practice. Ming novels, for example, describe large groups of competing and complementary practitioners. Acupuncture emerges as a lower class of practice, less prestigious than the prescription of Chinese medical drugs, and often the work of women. In Japan some of the most respected practitioners of acupuncture are found within the blind community.

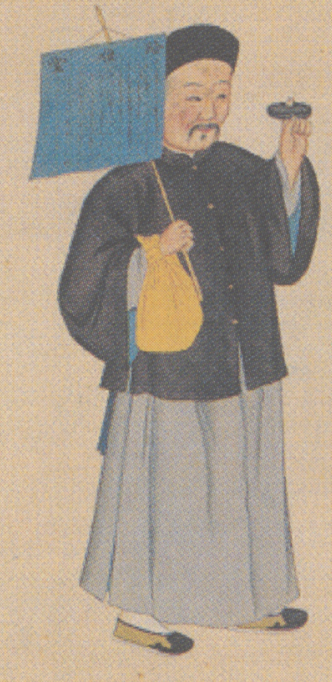

'Bell doctors' were itinerate physicians who called attention to their presence by ringing a bell.

Wellcome Library

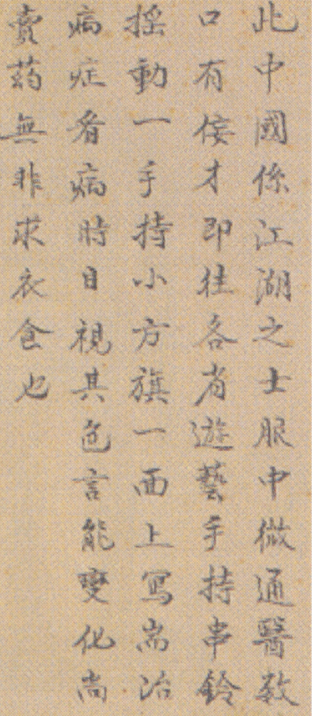




\section{Acupuncture in Late Imperial China (1368-1911)}

During the Ming and Qing dynasties the importance of acupuncture declined rapidly. Physicians like Zhang Jiebin (15631640) and $X u$ Dachun (1693-1771) noted that there were few well-known acupuncturists to be found in their time. In 1822, the Imperial Academy prohibited the teaching and practice of acupuncture. The reasons for this decline included a dislike of needles among patients, the emergence of gentler therapies such as tuina massage, and the preference of elite physicians for herbal medicine. Acupuncture was a manual therapy unsuited for the intellectual scholar-physicians that dominated the field of medicine. It became a specialist discipline often practised by 'external' medicine physicians as a part of a larger repertoire of petty surgery techniques.

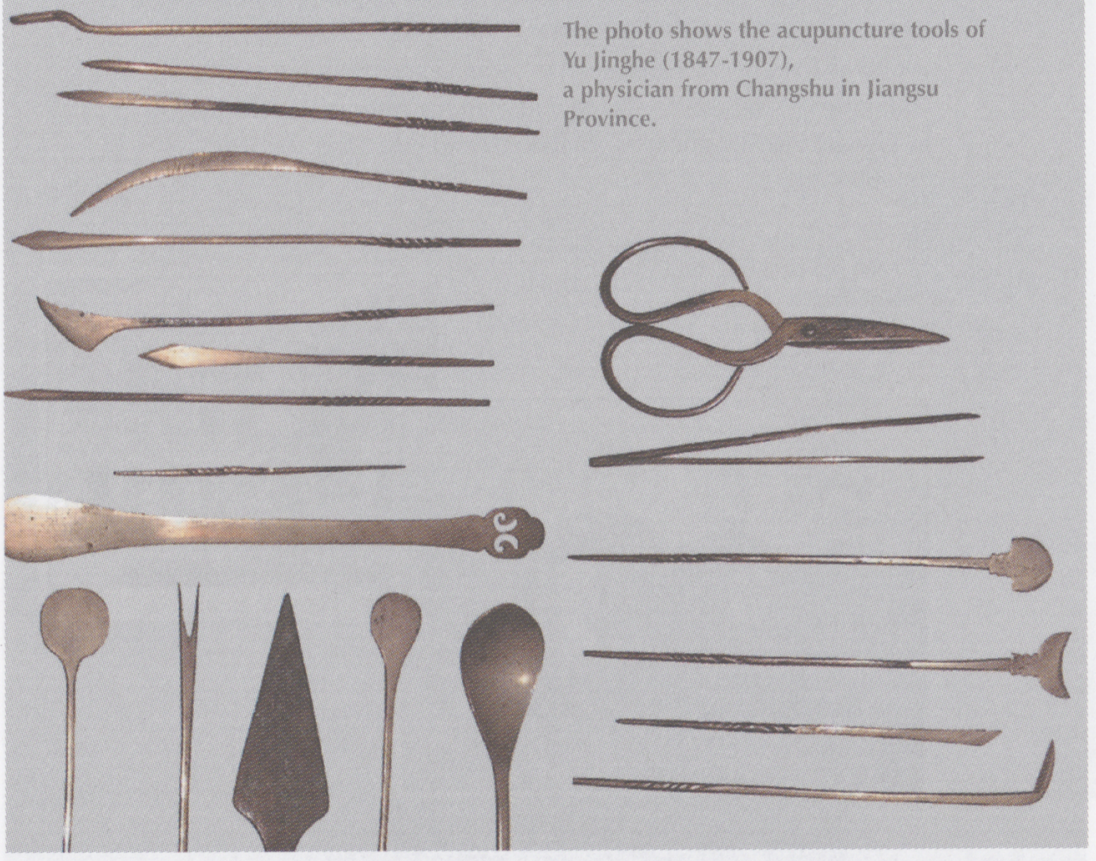




\section{The Modernisation of Chinese Medicine in Republican China (1911-1949)}

From the late nineteenth century onward, physicians of Chinese medicine increasingly advocated the need to modernize their tradition, if it was to survive in a rapidly changing society. This included the establishment of Western-style schools, colleges and hospitals, the founding of professional associations, and the publication of learned journals. During this period, traditional medicine also had to defend itself against efforts by more radical modernizers to disband its practice altogether.

In 1929, a motion intended to prohibit the practice of traditional medicine was put before parliament. In response, physicians of traditional medicine united for the first time in their history into one single group at a conference held in Shanghai on 17 March 1929. The conference sent a delegation to the capital Nanjing that successfully lobbied to have the motion deferred. The events of March 1929 are therefore seen as the birth of modern "traditional" Chinese medicine and March 17th is still celebrated in Taiwan and Singapore as "National Medicine Day."

The New China Chinese Medicine College in Shanghai and the 1929 Delegation to Nanjing.
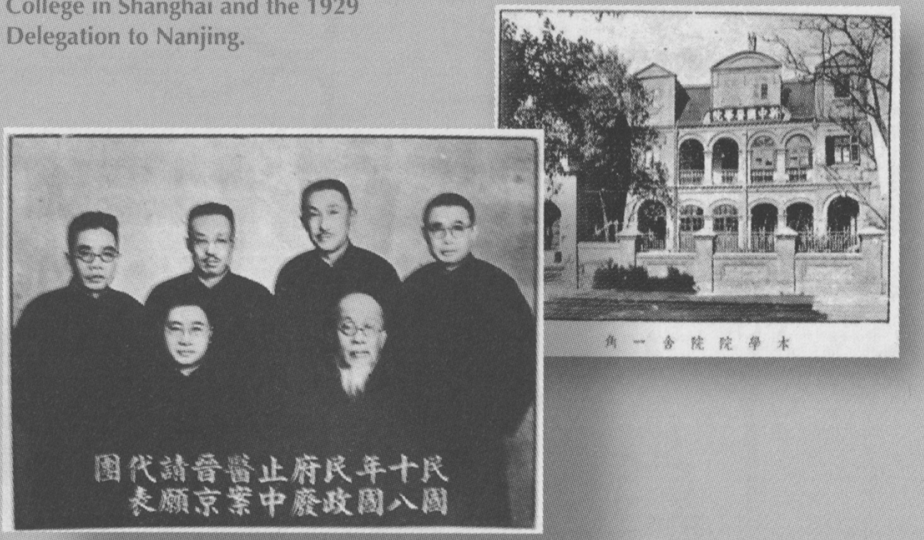
Calligraphy by Mao Zedong "Chinese medicine is a great treasure house and should be diligently explored and improved upon."
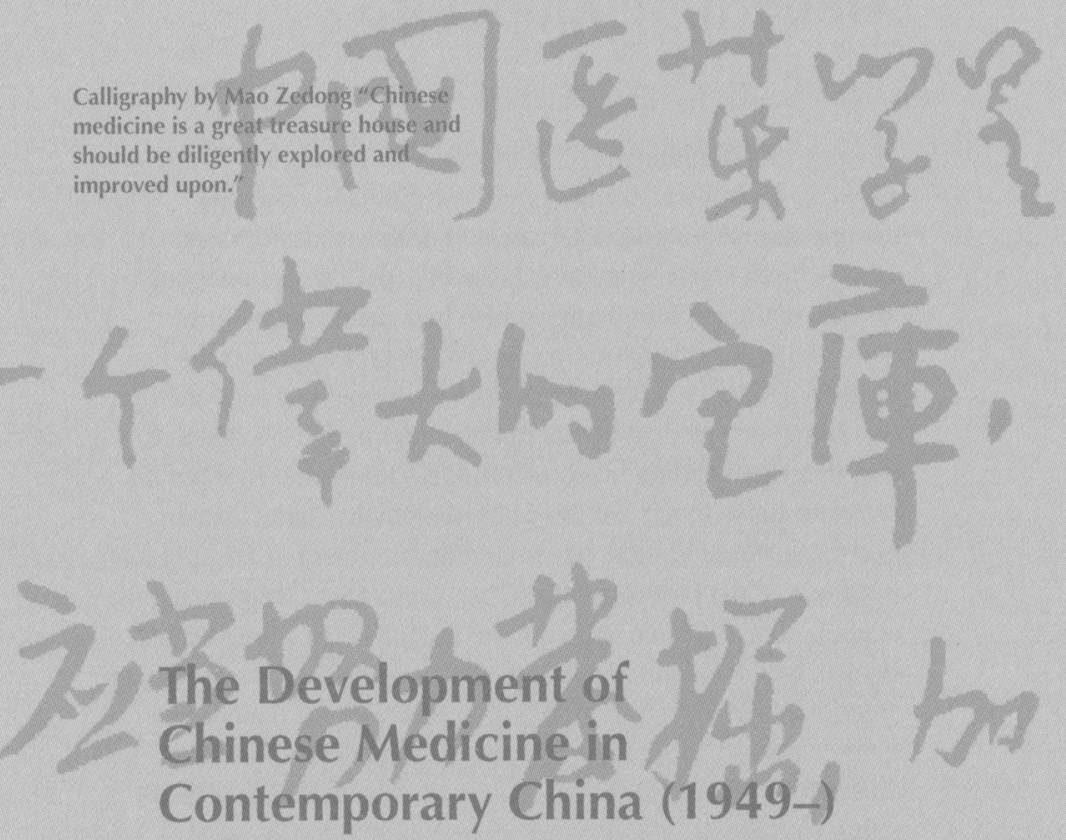

Chinese Communist leaders had long viewed Chinese medicine as a "feudal superstition." However, as Mao Zedong began to distance himself from the Soviet Union he changed his mind. Mao's Chinese communism focused on "patriotism," on "being self reliant" and "native" and Chinese medicine fitted this bill. From 1954 onward, it was used as a symbol for China's cultural genius. Colleges of Chinese Medicine were opened in Shanghai, Guangzhou, Chengdu and Beijing in 1956, and in 1958 Chinese medicine was declared a national treasure by the government. But Chinese medicine was not left to its own devices. It was expected to modernise, scientise, and eventually integrate with Western medicine. In the 1980s, it was defined by law as being part of a plural health care system in China and its infrastructure developed further. Since the 1990s, the Chinese government has made efforts to globalise Chinese medicine and to develop its economic potential. 


\section{Modern Acupuncture}

Poverty, lack of public health care and a general spirit of renewal stimulated some doctors in Republican China to promote acupuncture as a cheap alternative to drug based medicine. One of them was Cheng Dan'an (1899-1957), an acupuncturist and paediatrician from Jiangsu, who had visited Japan in the early 1930s. On his return to China in 1933, he opened the first modern acupuncture college in China in Wuxi. His acupuncture was based on classical theory but he attempted to systematize it in order to meet the needs of a modern audience. Through his students, his writings, and his political activity Cheng Dan'an exerted a profound influence on the development of acupuncture in China. At the same time that Chen Dan'an was developing his acupuncture in China, acupuncture in Japan also witnessed a revival, when acupuncturists like Yanagiya and Sawada developed "meridian therapy". Although promoted under the banner "return to the classics", this, too, was a distinctly modern innovation. Through its diffusion into Taiwan, Germany and France it has influenced the development of acupuncture in the West.
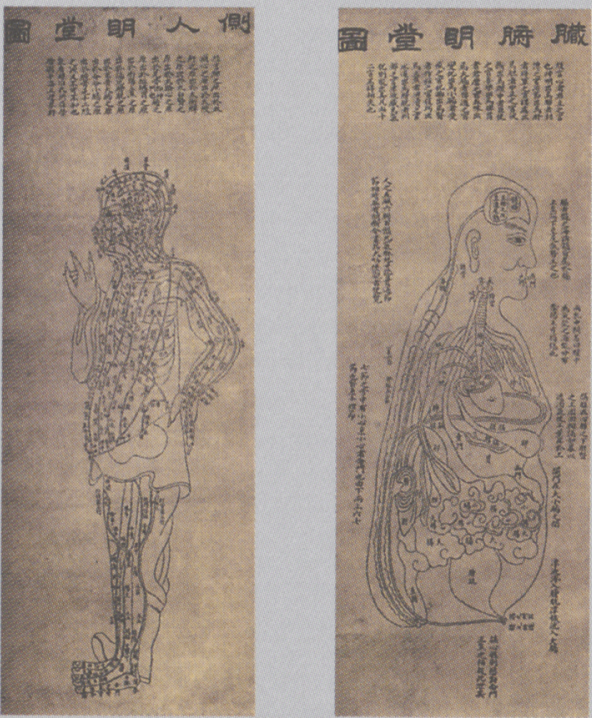

Sheets from a Ming (1368-1644) set of acupuncture charts. 